List of Changes in Taxonomic Opinion no. 4

Correspondence Jean Euzéby email address can be found at www.bacterio.net

\section{Notification of changes in taxonomic opinion previously published outside the IJSEM}

\begin{abstract}
The Bacteriological Code deals with the nomenclature of prokaryotes. This may include existing names (the Approved Lists of Bacterial Names) as well as new names and new combinations. In this sense the Code is also dealing indirectly with taxonomic opinions. However, as with most codes of nomenclature there are no mechanisms for formally recording taxonomic opinions that do not involve the creation of new names or new combinations. In particular, it would be desirable for taxonomic opinions resulting from the creation of synonyms or emended descriptions to be made widely available to the public. In 2004, the Editorial Board of the International Journal of Systematic and Evolutionary Microbiology (IJSEM) agreed unanimously that it was desirable to cover such changes in taxonomic opinions (i.e. the creation of synonyms or the emendation of circumscriptions) previously published outside the IJSEM, and to introduce a List of Changes in Taxonomic Opinion [Notification of changes in taxonomic opinion previously published outside the IJSEM; Euzéby et al. (2004). Int J Syst Evol Microbio/ 54, 1429-1430]. Scientists wishing to have changes in taxonomic opinion included in future lists should send one copy of the pertinent reprint or a photocopy or a PDF file thereof to the IJSEM Editorial Office or to the Lists Editor. It must be stressed that the date of proposed taxonomic changes is the date of the original publication not the date of publication of the list. Taxonomic opinions included in the List of Changes in Taxonomic Opinion cannot be considered as validly published nor, in any other way, approved by the International Committee on Systematics of Prokaryotes and its Judicial Commission. The names that are to be used are those that are the 'correct names' (in the sense of Principle 6) in the opinion of the bacteriologist, with a given circumscription, position and rank. A particular name, circumscription, position and rank does not have to be adopted in all circumstances. Consequently, the List of Changes in Taxonomic Opinion must be considered as a service to bacteriology and it has no 'official character', other than providing a centralized point for registering/indexing such changes in a way that makes them easily accessible to the scientific community.
\end{abstract}

\begin{tabular}{|lc|}
\hline Name/author(s): & Proposed as: \\
\hline Methylobacterium chloromethanicum McDonald et al. 2001 pro synon. & synon. \\
Methylobacterium extorquens (Urakami and Komagata 1984) Bousfield and Green 1985 & synon. \\
Methylobacterium dichloromethanicum Doronina et al. 2000 pro synon. & 2 \\
Methylobacterium extorquens (Urakami and Komagata 1984) Bousfield and Green 1985 & synon. \\
Methylobacterium lusitanum Doronina et al. 2002 pro synon. & 2 \\
Methylobacterium rhodesianum Green et al. 1988 & synon. \\
Pseudomonas chloritidismutans Wolterink et al. 2002 pro synon. & 1 \\
Pseudomonas stutzeri (Lehmann and Neumann 1896) Sijderius 1946 (Approved Lists 1980) & \\
\hline
\end{tabular}

For references to Lists of Changes in Taxonomic Opinion nos 1-3, see Int J Syst Evol Microbiol 55 (2005) 7, 1403; and 56 (2006) 11.

\section{References}

1. Cladera, A. M., Garcia-Valdés, E. \& Lalucat, J. (2006). Genotype versus phenotype in the circumscription of bacterial species: the case of Pseudomonas stutzeri and Pseudomonas chloritidismutans. Arch Microbiol 184, 353-361.
2. Kato, Y., Asahara, M., Arai, D., Goto, K. \& Yokota, A. (2005). Reclassification of Methylobacterium chloromethanicum and Methylobacterium dichloromethanicum as later subjective synonyms of Methylobacterium extorquens and of Methylobacterium lusitanum as a later subjective synonym of Methylobacterium rhodesianum. J Gen Appl Microbiol 51, 287-299. 